\title{
Preliminary phytochemical, antimicrobial and photochemical study of Calotropis gigantea leaf extract
}

\author{
Waseem Ahmad ${ }^{a^{*}}$
}

${ }^{a}$ Organic Chemistry Section, Department of Chemistry, Uttaranchal University, Dehradun 248001, India

\begin{tabular}{l} 
C H R O N I C L E \\
\hline Article history: \\
Received August 4, 2019 \\
Received in revised form \\
August 30, 2019 \\
Accepted September 27, 2019 \\
Available online \\
September 28, 2019 \\
\hline Keywords: \\
Phytochemical \\
Photochemical \\
Antibacterial activity \\
Antifungal activity \\
Calotropis gigantea \\
\\
\hline
\end{tabular}

\section{A B S T R A C T}

Several Plant products have been found to be a part of phytomedicines since time immemorial. These plant products can be derived from barks, leaves, flowers, roots, fruits, and seeds. It has been found that the light radiation affects the antimicrobial activity of herbal products. The present study was aimed to investigate the phytochemical screening and antimicrobial activities of Calotropis gigantea leaf extracts. In addition to these studies we also check the effect of UV light radiation on the anti microbial activity of leaf extract. Phytochemical screening revealed the presence of various active phytochemicals in the extracts of aerial part of Calotropis gigantea. Ethanol, chloroform and hexane extract of leaves were tested against Clostridium botulinum, Proteus vulgaris, Escherichia coli and Arthrographis cuboid, Aspergillus fumigatus, Aspergillus niger by the agar disc diffusion method. The antimicrobial activity of the extracts generally reduces significantly after exposure to the UV radiations.

(C) 2020 Growing Science Ltd. All rights reserved.

\section{Introduction}

Medicinal plants have been found to be the best source to obtain a variety of drugs. Medicinal plants produce bioactive compounds such as tannins, terpenoids, alkaloids, and flavanoids which have been proved in vitro to show anti microbial properties. ${ }^{1-4}$ The medicinal properties of plants may be based on the antioxidant, antimicrobial, antipyretic activity of the extract of different parts of the plant which is the consequences of the bioactive compound present in them..$^{5}$ The ability of herbal plants to synthesize a wide variety of chemical compounds has an important biological functions for example a defendence against attack from predators such as insects, fungi and herbivorous. ${ }^{6}$ The abundance of plants on the earth's surface has led to an increasing interest in the investigation of different extracts obtained from traditional medicinal plants, as potential source of new antimicrobial agents. ${ }^{7-9}$

Calotropis gigantea is one of the important herbal plants which are helpful in the treatment of various diseases of human being. ${ }^{10}$ Calotropis gigantea is a species of flowering plant within the family of Apocynaceae that is local to North Africa, Tropical Africa, Western Asia, South Asia, and Indochina. ${ }^{11}$ Calotropis gigantea has an anti-inflammatory activity. Its natural cleansing and astringent 
properties help in early healing of the wound, itching and healing skin diseases and spleen disorders. ${ }^{12-}$

${ }^{15}$ It is a digestive stimulant which eases out the digestive process making each and every organ function smoothly. ${ }^{16}$ It improves appetite which is combating anorexia and disinterest in eating meals. Nearby utility of this herb is very popularly utilized in Ayurvedic remedy practice to therapy hemorrhoids. It enables in shrinking hemorrhoid tags with its study alkaline movement. ${ }^{17}$ As a kapha pacifying herb, it allows in wholesome working of the respiration system, supporting in diseases like cough, cold, bronchial asthma and different similar breathing problems. ${ }^{18}$

The major challenges in herbal medicines are determining the overall quality, stability and efficiency of the herbal product. It is well known that the majority of herbal remedies are sensitive to the light and it has been reported that extracts of herbal plant may undergo photodegradation reactions on exposure to UV light. The aim of this study was therefore to evaluate the phytochemical and antimicrobial activity of calotropis gigantea leaf extract in addition to these studies we also check the effect of light irradiation on the antimicrobial activity of ethanolic leaf extract of Calotropis gigantea.

\section{Materials and methods}

\subsection{Plant Collection and Authentication}

The medicinal plant was collected from the Vikasnagar in Dehradun. The plant collected was identified botanically in department of Botany, F.R.I. The leaves and flowers of the selected plant were removed from the plants and then washed under running fresh water to remove dust. The plant was dried for a few days in the presence of sunlight after drying the plant material was crushed in a crusher and converted into powered form and stored into polythene bags before usage.

\subsection{Preparation of plant extracts}

\section{Solvent extraction}

Crude plant extract was prepared by Soxhlet extraction method. About $25 \mathrm{~g}$ of powdered plant material (leaves) was uniformly packed into a thimble and extracted with $250 \mathrm{ml}$ of different solvent (ethanol, chloroform, and hexane). All the extracts were evaporated using rotary evaporator and the percentage yield was thus recorded. Dried extracts were stored in airtight containers for further studies. Concentrated extracts were subjected to various chemical tests in order to detect the various phytoconstituents.

\section{Phytochemical Analysis}

The concentrated extract of selected plant was subjected to different chemical tests for the detection of different phytoconstituents using standard methods.

\subsection{Test for alkaloids}

Crude extract was dissolved in $2 \mathrm{~mL}$ of $1 \% \mathrm{HCl}$ and heated gently. Wagner's and Meyers reagents were added to the mixture. Turbidity of the resulting precipitate was taken as confirmation for the presence of alkaloids. ${ }^{19}$

\subsection{Test for flavonoid}

Crude extract when mixed with $10 \mathrm{~mL}$ distilled water; $5 \mathrm{~mL}$ of dilute ammonia solution were added to a portion of the aqueous filtrate solution then added $1 \mathrm{~mL}$ concentrated sulphuric acid. Indication of yellow color shows the presence of flavonoid. ${ }^{20}$ 


\subsection{Test for terpenoids}

Crude extract when mixed in $2 \mathrm{~mL}$ of chloroform and $3 \mathrm{~mL}$ of concentrated $\mathrm{H}_{2} \mathrm{SO}_{4}$ was added and mixed properly in selected sample extract. A reddish brown color was formed, the presence of terpenoids. $^{21}$

\subsection{Test for saponins}

Crude extract when mixed with $5 \mathrm{~mL}$ distilled water in a test tube then it was shaken briskly. The formation of stable foam which indicate the presence of saponins. ${ }^{22}$

\subsection{Test for carbohydrate}

$2 \mathrm{~mL}$ of Fehling A and Fehling B reagents were mixed together in equal volume. These reagents are added in crude extract and gently boiled. The bottom of the test tube a brick red precipitate is appeared and indicate the presence of reducing compounds. ${ }^{23}$

\subsection{Test for tannins}

Crude extract was mixed with water and heated on water bath. The mixture was filtered and ferric chloride was added to the filtrate. A dark green solution indicates the presence of tannins. ${ }^{24}$

\section{Bacterial culture}

The bacterial strain such as Proteus vulgaris, Escherichia coli and Clostridium botulinum were obtained from culture collection center department of biotechnology of Uttaranchal University, Dehradun and were maintained in Mueller Hinton agar at $4{ }^{\circ} \mathrm{C}$ for experiment studies. The different fungus strains such as Aspergillus niger, Arthrographis cuboid and Aspergillus fumigatus were isolated from potato dextrose agar.

\section{Preparation of standard culture inoculums of test organism}

The colonies of selected bacterial and fungal strains as mentioned in materials and methods were inoculated in the $50 \mathrm{~mL}$ nutrient broth and incubated for $24-72 \mathrm{~h}^{25}$

\section{Assay of anti-bacterial activity}

Assay of anti-bacterial activity of leaf extract of Calotropis gigantea was done by Disc Diffusion method. ${ }^{26} \mathrm{In}$ this method $20 \mathrm{~mL}$ of sterilized Mueller Hinton Agar was poured into sterile petri plates, after solidification, $120 \mu \mathrm{L}$ of bacterial culture poured on the plates and the culture was spread on plates using spreader. Then, the Whatmans filter paper discs ( $6 \mathrm{~mm}$ in diameter) were kept over the agar plates using sterile forceps at various concentrations. Concentrated solvent was used as negative control. The anti-bacterial assay plates were kept incubator, where all the plates were incubated at $37^{\circ} \mathrm{C}$ for $24 \mathrm{~h}$. The diameter of inhibition zone was noted down.

\section{Assay of anti-fungal activity}

Assay of anti-fungal activity of leaves extract of Calotropis gigantea was done by Disc Diffusion method ${ }^{26}$ In this method $20 \mathrm{~mL}$ of sterilized Mueller Hinton Agar was poured into sterile Petri plates, after solidification, $100 \mu \mathrm{L}$ of fungus culture poured on the plates and the culture was spread on plates using spreader. Then, the Whatmans filter paper discs (6 $\mathrm{mm}$ in diameter) were kept over the agar plates using sterile forceps at various concentrations. Concentrated solvent was used as negative control. The 
anti-fungus assay plates were kept incubator, where all the plates were incubated at $37^{\circ} \mathrm{C}$ for $24 \mathrm{~h}$. The diameter of inhibition zone was noted down.

\section{Photo irradiation}

The leaves extracts of Calotropis gigantea at a concentration of $1 \mathrm{mg} / \mathrm{mL}$ were prepared in the following solvents: ethanol, chloroform and hexane. Ethanol chloroform and hexane solution of the extract were irradiated with a mercury arc lamp with radiant energy at wavelength of $254 \mathrm{~nm}$ and emission power $8 \mathrm{~W} / \mathrm{cm}^{2} \mathrm{~W} / \mathrm{cm}^{2}$ for limited time period of about $4 \mathrm{~h}$. Antimicrobial activity of samples against the microorganism was evaluated after the period of irradiation.

\section{Result and Discussion}

Plants are playing vital role in having beneficial therapeutic effects in traditional Indian system of medicine. Studies on medicinal plants are gaining consensus in recent years in India and Abroad. In the present study, different leaf extract of calotropis gigantea were subjected to qualitative phytochemical analysis to explore its anti microbial activity for its medicinal applications.

The percentage yields of extracts and the phytochemical constituents of the plants are shown in Table 1 and Table 2, respectively. The highest yield of leaves extract was found when extraction was done with ethanol and the lowest in case of hexane. This is most probably due to change in the polarity of solvents. Ethanol is the highest and hexane is the lowest polar solvent.

Table 1. The Yield of extract with different solvent (\%)

\begin{tabular}{cccc}
\hline Plant Sample & $\begin{array}{c}\text { Ethanol Extract } \\
(\%)\end{array}$ & $\begin{array}{c}\text { Chloroform Extract } \\
(\%)\end{array}$ & $\begin{array}{c}\text { Hexane Extract } \\
(\%)\end{array}$ \\
\hline Leaves & 17.94 & 13.5 & 8.5 \\
\hline
\end{tabular}

Table 2. Preliminary phytochemical analysis of different leaves extract of calotropis gigantea

\begin{tabular}{llll}
\hline $\begin{array}{l}\text { Phytochemical } \\
\text { constituents }\end{array}$ & Ethanol & Chloroform & Hexane \\
\hline Alkaloids & $+(10.04 \mathrm{mg} / \mathrm{mL})$ & $+(9.5 \mathrm{mg} / \mathrm{mL})$ & - \\
Flavonoides & $+(11.2 \mathrm{mg} / \mathrm{mL})$ & $+(10.2 \mathrm{mg} / \mathrm{mL})$ & $+(9.3 \mathrm{mg} / \mathrm{mL})$ \\
Terpenoids & $+(9.2 \mathrm{mg} / \mathrm{mL})$ & $+(8.01 \mathrm{mg} / \mathrm{mL})$ & - \\
Tannins & $-(7.8 \mathrm{mg} / \mathrm{mL})$ & $+(8.5 \mathrm{mg} / \mathrm{mL})$ & - \\
Saponins & $+(6.5 \mathrm{mg} / \mathrm{mL})$ & $+(5.4 \mathrm{mg} / \mathrm{mL})$ & - \\
Carbohydrates & &
\end{tabular}

+ indicates presence of phytochemicals - = indicates absence of phytochemicals.

The result of the preliminary phytochemical screeing of different leaves extract of Calotropis gigantea shows in Table 2. The present study reveals that the phytochemical screening and qualitative estimation of leaves extract of Calotropis gigantea showed the presence of alkaloid, flavanoid, tannin, terpenoid and carbohyrate in choroform. In ethanolic extract of leaves alkaloid, flavanoid, sponins, carbohydrate and terpenoids are present.In the hexane extract of leaves only flavonoid is presnt.

\subsection{Antibacterial activity}

Result of the antibacterial activity of the isolated extract by using different solvent (ethanol, chloroform, and hexane) was showed in table 3. The dried leaves extract of Calotropis gigantea shown to posses' antibacterial activity. The antibacterial activity of ethanol, chloroform and hexane of extract 
of leaves of Calotropis gigantea were inspected against the selected experiment pathogens such as Proteus vulgaris, Clostridium and Escherichia Coli by disc diffusion method. The tested microbial organism shows varying degree of antibacterial activities in examined plant extract. The ethanol leaf extract of Calotropis gigantea showed the maximum zone of inhibition against in Clostridium botulinum $(35 \mathrm{~mm})$ which is gram positive bacteria and cause food poisoning, pneumonia and brain abscess. The hexane extract of leaves extract of Calotropis gigantea showed minimum zone of inhibition against Proteus vulgaris $(13 \mathrm{~mm})$.

Table 3. The growth-inhibitory diameters $(\mathrm{mm})$ of different extracts against the tested bacteria

\begin{tabular}{cccccc}
\hline \multirow{2}{*}{ Microorganisms } & \multicolumn{5}{c}{ Leaves Extract (zone of inhibition in mm) } \\
\cline { 2 - 6 } & Ethanol & $\begin{array}{c}\text { Ethanol } \\
\text { (control) }\end{array}$ & Chloroform & $\begin{array}{c}\text { Chloroform } \\
\text { (control) }\end{array}$ & Hexane \\
\hline Clostridium botulinum & 35 & 34 & 28 & 26 & 24 \\
Escherichia coli & 31 & 28 & 22 & 20 & 14 \\
Proteus vulgaris & 26 & 24 & 17 & 16 & 13 \\
\hline
\end{tabular}

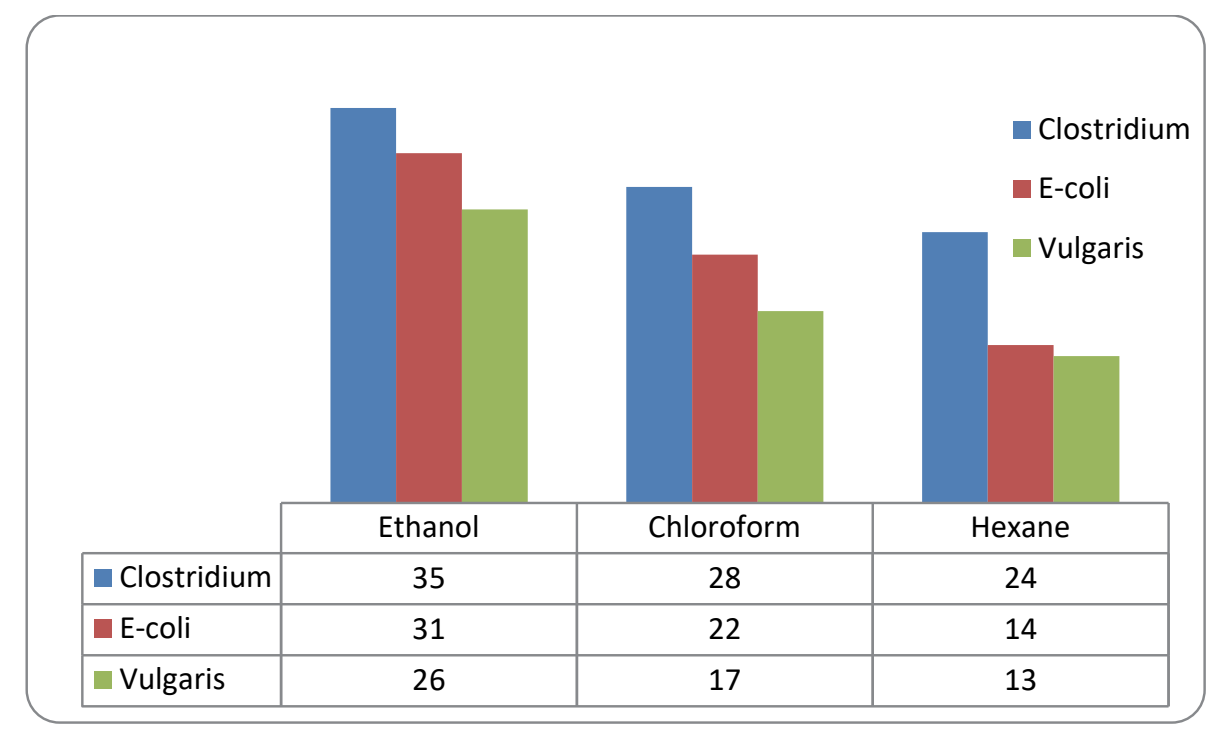

Fig. 1. The growth-inhibitory diameters $(\mathrm{mm})$ of different extracts against the tested bacteria

\subsection{Antifungal activity}

Antifungal activity is that anything that kills fungi or inhibits their growth or control of fungi infection. Antifungal is used to treat infection caused by a fungus. Antifungal drugs include amphoterin, griseofulvin, the lesimidazo, nystatin, teebinafine and tolnaftate. Result of the antifungal activity of the isolated extract by using different solvent (ethanol, chloroform, and hexane) was showed in Table 4. The antifungal activity of ethanol, chloroform and hexane of extract of dried leaves of Calotropis gigantea were inspected against the selected experiment pathogens such as Arthrographis cuboid, Aspergillus fumigatus and Aspergillus niger by disc diffusion method. The ethanol leaf extract of Calotropis gigantea showed the maximum zone of inhibition against in Arthrographis cuboid (38 mm). The hexane extract of leaves extract of Calotropis gigantea showed minimum zone of inhibition againest Aspergillus niger (12 mm). Minimum Inhibitory Concentration (MIC) of Calotropis gigantean was also determined and the result was shown in Table 5. 
Table 4. Antifungal activity of leaves of Calotropis gigantea

\begin{tabular}{cccccc}
\hline & \multicolumn{5}{c}{ Leaves Extract (zone of inhibition in mm) } \\
\cline { 2 - 6 } Microorganisms & Ethanol & $\begin{array}{c}\text { Ethanol } \\
\text { Control }\end{array}$ & Chloroform & $\begin{array}{c}\text { Chloroform } \\
\text { Control }\end{array}$ & Hexane \\
\hline Arthrographis cuboid & 38 & 29 & 32 & 30 & 25 \\
Aspergillus fumigates & 29 & 24 & 27 & 25 & 18 \\
Aspergillus niger & 25 & 21 & 21 & 20 & 12 \\
\hline
\end{tabular}

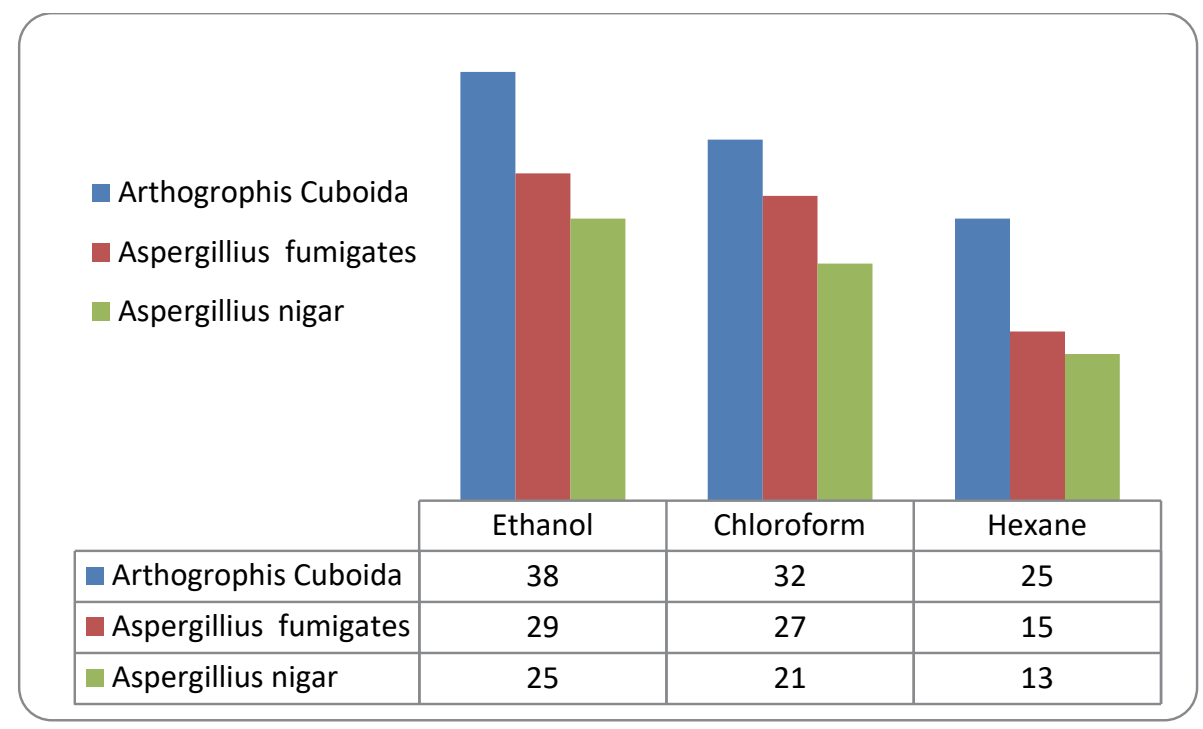

Fig. 2. Antifungal activity of leaves of Calotropis gigantea

Table 5. Minimum Inhibitory Concentration (MIC) of Calotropis gigantea

\begin{tabular}{cc}
\hline Tested organism & MIC of Calotropis gigantean, $\mathbf{~ m g} / \mathbf{m L}$ \\
\hline Proteus vulgaris & 4.5 \\
Escherichia coli & 6 \\
Clostridium botulinum & 3.5 \\
Aspergillus niger & 7 \\
Arthrographis cuboid & 8.5 \\
Aspergillus fumigatus & 6.5 \\
\hline
\end{tabular}

The ethanol leaves extract shows the maximum activity against bacterial and fungal strain hence we select ethanolic leaves extract for the study the effect of UV Light (254 nm for about $4 \mathrm{~h}$ ) on their antimicrobial activity. The evaluation of the antimicrobial activity of the irradiated samples (ethanolic sample) revealed a major loss of activity (Table 6 and Table 7). The decreases in the efficiency of irradiated sample most probably due to the photodegradtion of active compound which is mainly responsible for the cause structural modification of antimicrobial activity.

Table 5. Effect of UV light on antibacterial activity of ethanolic leaf extract of Calotropis gigantea

Microorganisms Zone of inhibition Zone of inhibition (treated)

(Non-treated)

\begin{tabular}{ccc}
\hline Proteus vulgaris & $26 \mathrm{~mm}$ & $18 \mathrm{~mm}$ \\
Escherichia coli & $31 \mathrm{~mm}$ & $21 \mathrm{~mm}$ \\
Clostridium botulinum & $35 \mathrm{~mm}$ & $25 \mathrm{~mm}$ \\
\hline
\end{tabular}


Table 6. Effect of UV light on antifungal activity of ethanolic leaf lextract of Calotropis gigantea

\begin{tabular}{ccc}
\hline Microorganism & $\begin{array}{c}\text { Zone of inhibition } \\
\text { (Non-treated) }\end{array}$ & $\begin{array}{c}\text { Zone of inhibition } \\
\text { (treated) }\end{array}$ \\
\hline Aspergillus niger & $25 \mathrm{~mm}$ & $14 \mathrm{~mm}$ \\
Arthrographis cuboid & $38 \mathrm{~mm}$ & $26 \mathrm{~mm}$ \\
Aspergillus fumigatus & $29 \mathrm{~mm}$ & $22 \mathrm{~mm}$ \\
\hline
\end{tabular}

\section{Conclusion}

Phytochemical analysis and antimicrobial study of any selected plant species is a very significant way to establish that the selected plant species may be use as potent drugs. In our present study we select commonly found plants Calotropis gigantea which is easily available in Dehradun. It is a well known remedy for inflammation of respiratory tract and for asthma as it has a special reputation for causing bronchial relaxation. It can also be used as diuretic and purgative action. The above points clearly illustrate that the plants studied here can be seen as a potential source of useful bioactive compounds. In this study, we found that the leaves extract of the plant contain large amount of alkaloids and flavonoid along with terpenoids, saponins, tannins and carbohydrate in small ration so these parts of the plant can be used as an important source of phytochemical and antimicrobial activity. On the basis of our antimicrobial study we find that our selected plant shows significant antibacterial activity against selected gram positive and gram negative strains. In addition to antibacterial study we also perform antifungal activity against selected fungal strains. So the study our results clearly indicate that we may use our plants as potent antibacterial drugs of natural origin. Furthermore we also established that the isolated leaf extract was photosensitive and their antimicrobial activity is remarkably decreases on exposure to UV light.

\section{References}

1. Nelly, A., Annick, D. D., \& Frederic, D. (2008). Plants used as remedies antirheumatic and antineuralgic in the traditional medicine of Lebanon. J. Ethnopharmacol, 120(3), 315-334.

2. Edziri, H., Mastouri, M., Mahjoub, M. A., Mighri, Z., Mahjoub, A., \& Verschaeve, L. (2012). Antibacterial, antifungal and cytotoxic activities of two flavonoids from Retama raetam flowers. Molecules, 17(6), 7284-7293.

3. Gawron-Gzella, A., Michalak, A., \& Kędzia A. (2014). Antimicrobial activity of preparation Bioaron C. Acta Pol. Pharm., 71(5) 795-802.

4. Abdel-Sattar, E. A., Mouneir, S. M., Asaad, G. F., \& Abdallah, H. M. (2014). Protective effect of Calligonum comosum on haloperidol-induced oxidative stress in rat. Toxicology and industrial health, 30(2), 147-153.

5. Ahmad, W., Singh, S., \& Kumar, S. (2017). Phytochemical screening and antimicrobial study of Euphorbia hirta extracts. J Med Plants Stud, 5, 183-186.

6. Alkhalifah, D. H. M. (2013). In-vitro antibacterial activity of ethanol extract of Calligonum comosum plant against four human pathogens in Saudi Arabia. Int. J. Plant, Animal and Env. Sci., 3(4), 2231-4490.

7. del Socorro Jimenez-Usuga, N., Malafronte, N., Cotugno, R., De Leo, M., Osorio, E., \& De Tommasi, N. (2016). New sesquiterpene lactones from Ambrosia cumanensis Kunth. Fitoterapia, 113, 170-174.

8. Usuga, N. D. S. J., Malafronte, N., Durango, E. J. O., Braca, A., \& De Tommasi, N. (2016). Phytochemical investigation of Pseudelephantopus spiralis (Less.) Cronquist. Phytochemistry let., 15, 256-259.

9. Marzocco, S., Adesso, S., Alilou, M., Stuppner, H., \& Schwaiger, S. (2017). Anti-Inflammatory and anti-oxidant potential of the root extract and constituents of Doronicum austriacum. Molecules, 22(6), 1003. 
10. Chattopadhyay, I., Biswas, K., Bandyopadhyay, U., \& Banerjee, R. K. (2004). Turmeric and curcumin: biological actions and medicinal applications. Current Science, 87(1), 44-53.

11. Ngan, N. T. T., Quang, T. H., Kim, K. W., Kim, H. J., Sohn, J. H., Kang, D. G., ... \& Oh, H. (2017). Anti-inflammatory effects of secondary metabolites isolated from the marine-derived fungal strain Penicillium sp. SF-5629. Arch. Pharm. Res., 40(3), 328-337.

12. Ranjit, P. M., Santhipriya, T., Nagasri, S., Chowdary, Y., Pasumarthy, N., \& Gopal, V. (2012). Preliminary phytochemical screening and antibacterial activities of ethanolic extract of Calotropis procera flowers against human pathogenic strains. Asian J Pharm Clin Res, 5, 127-131.

13. Alluri, N., \& Majumdar, M. (2014). Phytochemical analysis and in vitro antimicrobial activity of Calotropis gigantea, Lawsonia inermis and Trigonella foecum-graecum. Int J Pharm Pharm Sci, 6(4), 524-527.

14. Rajamohan, S., Kalaivanan, P., Sivangnanam, H., \& Rajamanickam, M. (2014). Antioxidant, Antimicrobial activities and GC-MS analysis of Calotropis gigantea white flowers. $J$. Phytopharmacology, 3(6), 405-409.

15. Kumar, G., Karthik, L., \& Bhaskara Rao, K.V. (2010) Antibacterial activity of aqueous extract of Calotropis gigantea leaves - an in vitro study. Int. J. of Pharma. Sci. Rev. and Res., 4 (2), 141-144.

16. Namrata, S., Jain, N. K., Pushpendra, K., Navneet, G., Pathak, A. K., \& Mehta, S. C. (2010). In vitro antioxidant activity of Calotropis gigantea hydroalcohlic leaves extract. Der Pharmacia Lettre., 2(3), 95-100.

17. Chitme, H. R., Chandra, R., \& Kaushik, S. (2005). Evaluation of antipyretic activity of Calotropis gigantea (Asclepiadaceae) in experimental animals. Phytotherapy Res., 19(5), 454-456.

18. Shilpkar, P., Shah, M., \& Chaudhary, D. R. (2007). An alternate use of Calotropis gigantea: Biomethanation. Curr. Sci., 92(4), 435-437.

19. Dorantes, L., Colmenero, R., Hernandez, H., Mota, L., Jaramillo, M. E., Fernandez, E., \& Solano, C. (2000). Inhibition of growth of some foodborne pathogenic bacteria by Capsicum annum extracts. Int. J. Food Microb., 57(1-2), 125-128.

20. Nascimento, G. G., Locatelli, J., Freitas, P. C., \& Silva, G. L. (2000). Antibacterial activity of plant extracts and phytochemicals on antibiotic-resistant bacteria. Brazilian J. Microb., 31(4), 247-256.

21. Ngarmsak, M., Delaquis, P., Toivonen, P., Ngarmsak, T., Ooraikul, B., \& Mazza, G. (2006). Antimicrobial activity of vanillin against spoilage microorganisms in stored fresh-cut mangoes. $J$. Food prot., 69(7), 1724-1727.

22. Ahmad, W., Kumar, P., Chaturvedi, A. K. (2019). Study the effect of UV light on the antimicrobial activity of Euphorbia hirta leaf extract. J. Pharm. Phytochem., 8(2), 1737-1740

23. Roller, S., \& Seedhar, P. (2002). Carvacrol and cinnamic acid inhibit microbial growth in freshcut melon and kiwifruit at $4^{\circ}$ and $8^{\circ}$ C. Lett. Appl. Microbiol., 35(5), 390-394.

24. Rupasinghe, H. V., Boulter-Bitzer, J., Ahn, T., \& Odumeru, J. A. (2006). Vanillin inhibits pathogenic and spoilage microorganisms in vitro and aerobic microbial growth in fresh-cut apples. Food Res. Int, 39(5), 575-580.

25. Soni, A., \& Sosa, S. (2013). Phytochemical analysis and free radical scavenging potential of herbal and medicinal plant extracts. J. Pharm. Phytochem., 2(4), 22-29.

26. Upadhyay, P., Mishra, S. K., Purohit, S., Dubey, G. P., Chauhan, B. S., \& Srikrishna, S. (2018). Antioxidant, antimicrobial and cytotoxic potential of silver nanoparticles synthesized using flavonoid rich alcoholic leaves extract of Reinwardtia indica DOI: 10.1080/01480545.2018.1488859.

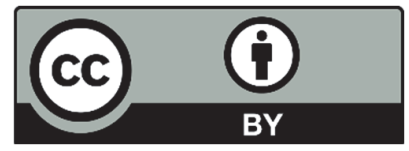

(C) 2020 by the authors; licensee Growing Science, Canada. This is an open access article distributed under the terms and conditions of the Creative Commons Attribution (CC-BY) license (http://creativecommons.org/licenses/by/4.0/). 